\title{
The Physics Governing the Operation of Cages in an Aquaculture Farm: A Case Study from South Australia
}

\author{
John A T Bye* \\ School of Earth Sciences, The University of Melbourne, Australia \\ Submission: February 27, 2020; Published: March 19, 2020 \\ Corresponding author: John AT Bye, School of Earth Sciences, The University of Melbourne, Victoria 3010, Australia
}

\section{Introduction}

The successful operation of fish farms is of paramount importance. This short paper summarizes the environmental physics which applies in a vertically well mixed water body in a coastal location maintained by tidal exchange, which is where most productive fish farms are located. Analytical formulae are given which are easily applied from basic oceanographic data and the fish stock which is proposed for the cages in the aquaculture farm. No specialist oceanographic knowledge is assumed for the implementation of the formulae, as is demonstrated from a case study for an aquaculture farm in South Australia.

The Parameters which Predict the Behaviour of the Fish Farm

\section{Section 2.1: The Specification of the Well Mixed Tidal Environment}

The controlling mixing coefficient for the tidal environment is the coefficient of vertical eddy viscosity, $K_{V}=a U_{T}^{2} T_{o} /(2 \pi)$ where $\mathrm{U}_{\mathrm{T}}$ is the amplitude and $\mathrm{T}_{0}$ is the period of the tidal current, and a $=710^{-6}[1]$, and the mixing time, $T_{V}=(H / \pi)^{2} / K_{v}$, in which $\mathrm{H}$ is the water depth. In a vertically well mixed environment, the mixing time $\left(\mathrm{T}_{\mathrm{V}}\right)$ is much less than the tidal period $\left(\mathrm{T}_{\mathrm{o}}\right)$.

\section{Section 2.2: The Material Balance in the Aquaculture Cage}

The mean concentration of material in the cage due to the fish farming, $c_{m}=F T_{c}$ where $\mathrm{F}\left(\mathrm{kg} / \mathrm{m}^{3} / \mathrm{s}\right)$ is the specific source flux of material, and $\mathrm{T}_{c}$ is the cage time constant. For a cylindrical cage of diameter (D) and depth (h), $T_{c}=\left(1 / 4 \pi D^{2} h\right) /\left(\pi D h U_{c}\right)=1 / 4 D / U_{c}$ where $U_{c}$ is the stirring velocity which disperses the material through the cage perimeter.

\section{Section 2.3: The Stirring Velocity and the Cage Time Constant}

We need now to determine the stirring velocity for the ventilated cage This can be done by considering a cage which is situated in a tidal stream of ambient concentration $\left(c_{0}\right)$. The ventilated cage is subject to an influx, $J=D h|U| c_{o}$ where

$U=U_{T} \sin 2 \pi t / T_{o}$ is the tidal current during the tidal cycle. Hence the material budget for the cage is,

$$
d\left(1 / 4 \pi h D^{2} c\right) / d t=J+1 / 4 \pi h D^{2} F-\pi D h U_{c} c
$$

The steady-state solution of this equation for the mean concentration in the well mixed cage is, $c=F T_{c}+c_{o}\left\langle|U|>/\left(\pi U_{c}\right)\right.$ where $\langle|U|\rangle=U_{T} / \pi$ is the mean value of the inflowing tidal current during the tidal cycle. On substituting for $\langle|U|>$ and setting $c=c_{o}+c_{m}$ we find that since the ambient material concentration is $c_{o}$, the stirring velocity due to the tidal motion, $U_{c}=U_{T} / \pi^{2}$, and hence that the cage time constant, $T_{c}=1 / 4 D \pi^{2} / U_{T}$.

\section{Section 2.4: The Range of Material Concentration in the Cage due to Ventilation}

On considering the material budget equation at the maximum, $|U|=U_{T}$, and the minimum, $|U|=0$ of the inflowing tidal current, we also find that the concentration in the cage due to ventilation with the environment, which has a mean value of $c_{o}$, ranges from $\pi c_{o}$ to 0 .

These relations enable the hydrodynamics of any aquaculture farm to be readily assessed.

Case Study for the Aquaculture Farm in Spencer Gulf, South Australia

The South Australian aquaculture farm is in Boston Bay in southern Spencer Gulf (Figure 1). The cages are situated in a water depth $(\mathrm{H})$ of about $20 \mathrm{~m}$, and in a semi-diurnal tidal stream amplitude, $\mathrm{U}_{\mathrm{T}}=25 \mathrm{~cm} / \mathrm{s}$ at Spring tide [2]. Hence from Section 2.1, at Spring tide, $\mathrm{K}_{\mathrm{v}}=30 \mathrm{~cm}^{2} / \mathrm{s}$ and the mixing time, $\mathrm{T}_{\mathrm{v}}=3.8 \mathrm{hrs}$, which is much less than the tidal period, $\mathrm{T}_{\mathrm{o}}=12.4 \mathrm{hrs}$, so that vertically well mixed conditions apply, which would be expected to persist throughout the tidal cycle. 
In the Boston Bay aquaculture farm, there are 150 cages of diameter $(\mathrm{D}=40 \mathrm{~m})$ and cage depth $(\mathrm{h}=10 \mathrm{~m})$ and in the growout season about $350 \mathrm{t} /$ month of nitrogen is excreted [3]. Hence the source flux of $\mathrm{NO}_{3} /$ cage is $4 \mathrm{~g} / \mathrm{s}$, and the specific flux, $\mathrm{F}=3$ $10^{-7} \mathrm{~kg} / \mathrm{m}^{3} / \mathrm{s}$. The ambient concentration of $\mathrm{NO}_{3}$ in the grow out season, $c_{o}=4 \mu \mathrm{g} / l[4]$.

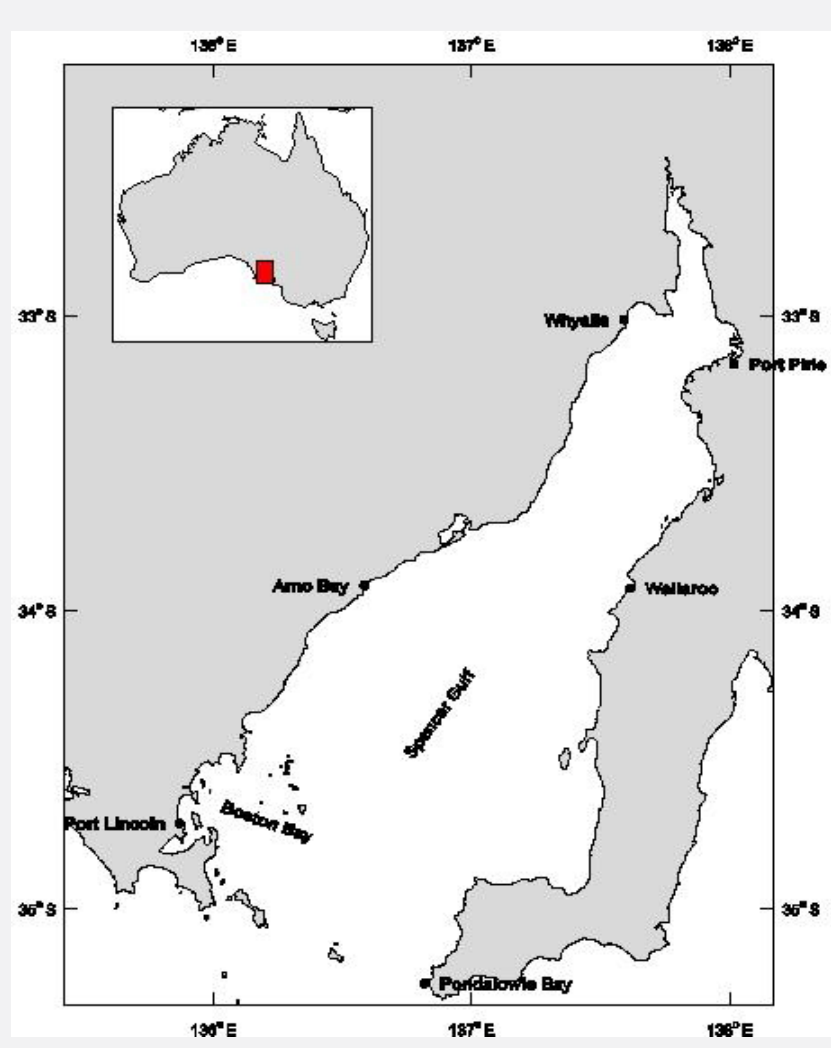

Figure 1: Boston Bay, South Australia.

For these conditions, the stirringvelocity, $U_{c}=2.5 \mathrm{~cm} / \mathrm{s}$, the cage time constant, $\mathrm{T}_{\mathrm{c}}=395 \mathrm{~s}$ (Section 2.3) and the mean concentration of $\mathrm{NO}_{3}$ in the cage due to the fish farming, $c_{m}=120 \mu \mathrm{g} / \mathrm{l}$ (Section 2.2 ), and the increase in ambient cage concentration at maximum ebb and flow over slack water is $12 \mu \mathrm{g} / \mathrm{l}$, which is about $10 \%$ of the mean cage concentration $\left(c_{o}+c_{m}\right)$ of $124 \mu \mathrm{g} / \mathrm{l}$ (Section 2.4). The mean cage concentration is also about 30 times the ambient concentration. This is reflected in the sediment nutrient stores, which were more than seven times background levels during the farming season [4].

\section{Conclusion}

An expression has been derived for the cage time constant in a vertically well mixed tidal environment (A) from which the mean material concentration due to fish farming can be derived (B and C). Another expression is also presented which predicts the variability in cage concentration due to the ventilation of the cage with its tidal environment (D). Both these expressions can be readily evaluated, without the necessity for an extensive field programme as demonstrated for the aquaculture farm in Spencer Gulf, South Australia.

\section{References}

1. Bye J A T (1990) Richardson Number profiles in laboratory experiments applied to shallow seas. Geophysics \& Astrophysics Fluid Dynamics 51: 136-166.

2. Herzfeld M, Middleton JF, Andrewartha JR, Luick J and W Leeying (2008) Numerical modelling of Boston Bay Spencer Gulf. Aquafin CRC 342: 100 .

3. Fernandes M, Lauer P, Cheshire A and M Angove (2007) Preliminary model of nitrogen loads from southern bluefin tuna aquaculture. Mar Pollut Bull 54(9): 1321-1332.

4. Benetti D D (2000) Aquaculture of pelagic fish: Offshore cage culture of southern bluefin tuna (Thunnus maccoyii) in South Australia. Global Aquaculture Alliance: The Advocate 28-29. 
(C) (1) This work is licensed under Creative

BY DOI: 10.19080/OFOAJ.2020.11.555824
Your next submission with Juniper Publishers will reach you the below assets

- Quality Editorial service

- Swift Peer Review

- Reprints availability

- E-prints Service

- Manuscript Podcast for convenient understanding

- Global attainment for your research

- Manuscript accessibility in different formats ( Pdf, E-pub, Full Text, Audio)

- Unceasing customer service

Track the below URL for one-step submission https://juniperpublishers.com/online-submission.php 